\title{
HIV treatment under control - now for sexy prevention?
}

The South African (SA) government launched a ZAR2 billion HIV prevention and young women empowerment programme, the biggest this country has ever seen, at the Pietermaritzburg Showgrounds on 24 June - and healthcare workers may soon start selling sexual pleasure as a prevention tool. The multisector, 3-year overseas-funded campaign, to be supplemented by an as-yet-undisclosed Treasury amount, also aims to reduce teenage pregnancies and gender-based violence, keep girls in school, and create economic opportunities.

Speaking to Izindaba before the launch, Dr Fareed Abdullah, CEO of the South African National AIDS Council, embraced the 'pleasure principle' as part of a multipronged strategy to promote the poorly used female condom. Knowledge of Femidoms among 15-year-old girls is measured at $78 \%$, but use at just $7 \%$. 'It's a great way to think about it because it's the most effective women-controlled HIV prevention method. We'd like to increase its attractiveness to both sexes', he added. Asked why the strategy was being considered so belatedly, he responded: 'In all honesty, we haven't embraced it. We talk about HIV a lot, but not about sex and pleasure and how they drive new infections. I'm very open to those making the case and who have the expertise.'

SA increased the distribution of condoms from 353 million in 2013 to 723 million in
2015, and of Femidoms from 7.6 million in 2013 to 20.7 million last year. While the treatment push has reaped rich rewards, paradoxically contributing to an HIV prevalence hike (10-12\% from 2008 to 2012 , i.e. more people surviving), an increasing incidence, especially among younger women, is now the big worry. Studies estimate that 1700 women between the ages of 18 and 24 years are being infected with HIV every week (latest incidence $2.8 \%$ ).

\section{Chris Bateman}

chrisb@hmpg.co.za

S Afr Med J 2016;106(8):749.

DOI:10.7196/SAMJ.2016.v106i8.11232 